\title{
Fruit and vegetable consumption close to recommendations. A partly web- based nationwide dietary survey in Swedish adults
}

\author{
Anna-Mari Simunaniemi*, Agneta Andersson and \\ Margaretha Nydahl \\ Department of Food, Nutrition and Dietetics, University of Uppsala, Uppsala, Sweden
}

\section{Abstract}

Background: Fruit and vegetables $(\mathrm{F} \& \mathrm{~V})$ are strongly associated with health. The latest Swedish national dietary survey from a decade ago showed that consumption of F\&V was below recommended levels. However, current consumption in different subgroups is not well known.

Objective: To investigate the consumption of various F\&V types in Swedish adults grouped according to sociodemographic factors and self-reported physical activity (PA).

Design: A cross-sectional survey using a quantitative pen-and-paper or web-based questionnaire in a population-based random sample of adults $18-84$ years (final $n=1,304 ; 51 \%$ ). A self-administered 24-h recall and a food frequency questionnaire (FFQ) were used to measure F\&V consumption. Data on gender, age, education level, country of birth, and PA (hours/week) were included as grouping variables. Besides descriptive data, two-sample $t$-tests and non-parametric tests were performed. A $P$-value $<0.01$ was regarded as significant.

Results: Mean F\&V consumption based on the self-administered 24-h recall was close to the recommended five portions/day: 5.4 (99\% CI 5.1-5.6) portions/day among women and 4.7 (4.4-5.0) portions/day among men $(P<0.001)$. Also the FFQ showed that women generally consumed more $\mathrm{F} \& \mathrm{~V}$ than men did. Consumption was lowest among respondents with $\leq 0.5 \mathrm{~h}$ self-reported PA/week $(P \leq 0.001)$, as well as among men born in Sweden $(P=0.006)$. F\&V were consumed in almost equal amounts, and fresh $\mathrm{F} \& \mathrm{~V}$ were most popular. Intake of berries and cooked F\&V was relatively low.

Conclusion: The present study shows a relatively high F\&V consumption close to the recommended five portions per day. Gender differences still exist. Also PA and country of birth were significantly associated with F\&V consumption.

Keywords: fruit and vegetables; dietary survey; physical activity; questionnaire; web-based

$\mathrm{H}$ igher fruit and vegetables (F\&V) consumption has been associated with a reduced risk for cardiovascular disease $(1,2)$, cancer $(3-6)$ and stroke (7), and reduced mortality (8). A total of 2.7 million deaths annually are estimated to be attributable to low $\mathrm{F} \& \mathrm{~V}$ consumption (9). Authorized bodies worldwide recommend eating at least $400 \mathrm{~g}$ of $\mathrm{F} \& \mathrm{~V}$ per day $(3,10$, 11 ), which is estimated to be equivalent to approximately five portions (12). However, the latest Swedish nationwide food consumption survey from a decade ago showed that an average $\mathrm{F} \& \mathrm{~V}$ consumption (excluding potatoes) was around 4 times/day among women and 2.8 times/day among men (13). Another, less comprehensive survey from 2006 indicated that only $12 \%$ of women and $4 \%$ of men between 18 and 84 years consumed five or more F\&V portions per day (14). However, detailed information on the different types of $F \& V$ consumed and information on respondents' sociodemographic variables were not reported.

It has been suggested that several factors, such as gender, age, education, living conditions, and lifestyle are associated with $\mathrm{F} \& \mathrm{~V}$ consumption. Men generally consume 
less F\&V than women do (15-18), and particularly older women have reported higher F\&V consumption than younger women have (19). Further, men living on their own consume significantly less fruit than do cohabiting men $(20,21)$, and being married has been strongly associated with higher vegetable consumption (22). Also higher education $(16,18,19,22-27)$ and physical activity (PA) $(22,24,25,28)$ have been strongly associated with higher consumption.

During recent years, imported fresh or processed fruit, fresh-cut raw salads, and other new types of F\&V are being sold in increasing amounts (29). Knowledge about and understanding of what affects $\mathrm{F} \& \mathrm{~V}$ consumption in different population groups is essential for determining whether this product development has affected F\&V consumption as well as for identifying which sub-groups have the lowest consumption and should be the targets of $\mathrm{F} \& \mathrm{~V}$ promotion projects. A decade has passed since the latest nationwide food consumption survey among Swedish adults was conducted. The present study focuses particularly on current $\mathrm{F} \& \mathrm{~V}$ consumption in different demographic groups as well as to collect detailed information on the different types of $F \& V$ consumed. The aim of the present study was to investigate how consumption of different $\mathrm{F} \& \mathrm{~V}$ types is related to demographic factors such as age, gender, education, and country of birth, in a randomly selected nationwide sample of Swedish adults.

\section{Material and methods}

An age-group stratified (18-24, 25-34, 35-44, 45-54, 5564, 65-74, and 75-84 y) geographically representative random sample of 2,604 Swedish inhabitants with an equal number of women and men was selected by Swedish National Tax Agency in 2007. The respondents were divided into equally large summer and autumn groups to cover the possible seasonal variation in $\mathrm{F} \& \mathrm{~V}$ consumption. A questionnaire enclosed with an invitation letter was sent out by mail. The respondents were also given a web-based questionnaire as an alternative measure; this was done to encourage respondents who find a traditional pen-and-paper questionnaire too time-consuming to complete the survey. As compensation, the respondents could receive a short report of the main results of the study, if they wished. A few weeks after the first circular, a reminder letter was sent to the non-responders. To increase the response rate, a second reminder was sent to all nonrespondents in January 2008. For a detailed picture of the study design, see Fig. 1. The returned questionnaires were treated confidentially, the respondents gave their informed consents, and The Swedish Research Council's guidelines for good research practice (30) were followed in conducting the present study.

\section{Measurements}

Detailed information regarding consumption of different kinds of F\&V was collected using a 13-item self-administered 24-h recall and a 12-item food frequency questionnaire (FFQ). Respondents were asked to report consumed amounts either in deciliters or number of portions in the self-administered 24-h recall (e.g. 'Did you eat apples yesterday and, if yes, how many?'). The FFQ included eight response categories for each item ('never,' 'less than once/week, 'once/week,' '2-4 times/week,' '5-6 times/week,' 'once/day,' two times/day,' and 'more than twice a day'), indicating the average consumption frequencies for salad/ raw and cooked vegetables as well as for fresh fruit and fruit juice (e.g. 'How often do you usually eat fresh fruit?').

Both the FFQ and the self-administered 24-h recall were based on a validated questionnaire where no differences were observed between the 24-h recall and one-day weighed food record of F\&V (31). In addition, the FFQ showed a correlation coefficient of 0.73 for total F\&V with a seven-day food record (31). The present questionnaire was also pre-tested on 20 Swedish adults, and one focus group interview $(n=5)$ was held in which respondents discussed $\mathrm{F} \& \mathrm{~V}$. Minor adjustments were made on the basis of comments from the pilot tests.

Mean daily consumption of different types of fruits, vegetables, as well as total consumption (including berries and juice, excluding potatoes) on a population-level was calculated from the self-administered 24-h recall. The FFQ was used for analyzing typical consumption frequencies over a longer time period. Data on different sociodemographic variables (gender, age, household size, country of birth, and level of education) are presented in Table 1. Level of PA was measured by asking how many hours per week the respondents engage in exercise that causes them to perspire or become breathless.

\section{Statistics}

The analyses were undertaken separately for women and men as well as for different demographic groups. Means and $99 \%$ confidence intervals $[99 \%$ CIs] were calculated for daily $F \& V$ consumption (portions/day). Respondents reporting unusually high consumption of $>15 \mathrm{~F} \& \mathrm{~V}$ portions/day were excluded from the analyses (five men and five women). Two-sample $t$-tests and one-way ANOVA were used to determine whether mean F\&V consumption from the self-administered 24 -h recall differed between subgroups. Where needed, differences between subcategories were analyzed using Tukey's post-hoc test. Based on normality tests and regarding the large sample size, the variable was used in its original form. MannWhitney test was used to analyze consumption data from the FFQ. Due to the large number of significance tests conducted, a $P$-value $<0.01$ (two-sided) was considered statistically significant throughout the study. All statistical analyses were performed using SPSS 16.0 (32). 


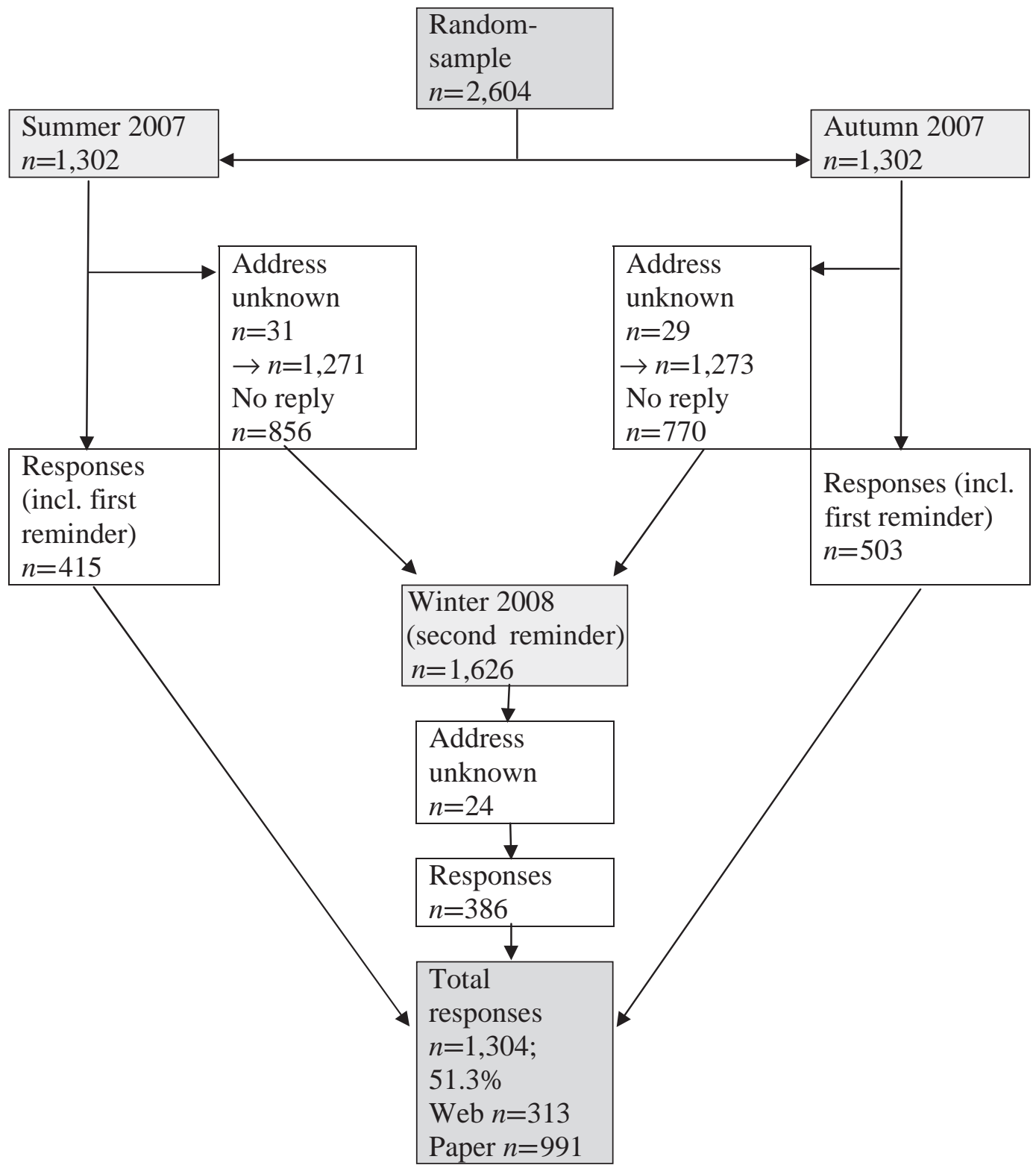

Fig. 1. The study design.

Results

A total of 1,304 questionnaires were returned and properly filled out, giving a response rate of $51 \%$. Approximately one-third of the respondents chose the web-based questionnaire. There were more women than men (56\% vs. $44 \%)$ among the respondents. The respondents are geographically representative of the whole of Sweden. Most respondents (79\%) lived with another person. Roughly one-third (37\%) had a university-level education, and $49 \%$ had been employed during the past six months. About $12 \%$ of the respondents were born outside Sweden, compared to roughly $17 \%$ in the total Swedish population (33). Sociodemographic characteristics of the respondents and total F\&V consumption in each subgroup are presented in Table 1.

\section{Consumption in different demographic groups}

According to the self-administered 24-h recall, total F\&V consumption was $2.2(99 \%$ CI 2.0-2.4) portions per day in the lowest quartile among women $(n=187)$ and 1.9 (1.7-2.1) daily portions among men $(n=201)$. The highest quartile of women $(n=159)$ consumed $9.9(9.3-10.4)$ portions on the examined day compared to 9.4 (8.4-10.5) portions among men $(n=143)$. Mean number of total F\&V portions varied from 4.9 to 5.8 among women and 4.2 to 5.0 among men in different age groups, but consumption did not differ statistically across age groups. Men born in Sweden had lower total F\&V consumption than did men born in another country $(P=0.006)$. Women with $\leq 0.5 \mathrm{~h}$ self-reported PA/week had lower $\mathrm{F} \& \mathrm{~V}$ consumption than those reporting $\geq 1 \mathrm{~h} \mathrm{PA} /$ week 
Table 1. Respondent characteristics and fruit and vegetable consumption (portions/day) according to the self-administered 24-h recall

\begin{tabular}{|c|c|c|c|c|c|c|c|c|}
\hline \multirow[t]{2}{*}{ Grouping variable } & \multicolumn{4}{|c|}{ Women (total $n=732$ ) } & \multicolumn{4}{|c|}{ Men (total $n=572$ ) } \\
\hline & $N(\%)$ & Mean & $99 \% \mathrm{Cl}$ & $P$ & $N(\%)$ & Mean & $99 \% \mathrm{Cl}$ & $P$ \\
\hline All ages & 723 & 5.4 & $5.1-5.6$ & & 565 & 4.7 & $4.7-5.0$ & \\
\hline $18-24 y$ & $92(13)$ & 5.2 & 4.46 .0 & $n s^{a}$ & $5 I(9)$ & 4.2 & $3.1-5.4$ & $n s^{\mathrm{a}}$ \\
\hline $25-34 y$ & $108(15)$ & 5.1 & $4.4-5.8$ & & $76(13)$ & 4.5 & $3.6-5.5$ & \\
\hline $35-44 y$ & $109(15)$ & 4.9 & $4.2-5.5$ & & $69(12)$ & 4.7 & $3.7-5.7$ & \\
\hline $45-54$ y & $112(15)$ & 5.4 & $4.7-6.1$ & & $79(14)$ & 4.7 & $3.9-5.5$ & \\
\hline $55-64 y$ & $127(18)$ & 5.8 & $5.2-6.5$ & & $92(16)$ & 4.5 & $3.9-5.1$ & \\
\hline $65-74$ y & $110(15)$ & 5.6 & $4.9-6.2$ & & $103(18)$ & 5.0 & $4.2-5.8$ & \\
\hline $75-84 y$ & $63(9)$ & 5.5 & $4.7-6.4$ & & $95(17)$ & 4.8 & $3.9-5.6$ & \\
\hline Single household & $153(20)$ & 5.1 & $4.5-5.6$ & $n s^{\mathrm{b}}$ & $120(22)$ & 4.7 & $4.0-5.3$ & $n s^{\mathrm{b}}$ \\
\hline Multi-person household & $560(20)$ & 5.5 & $5.2-5.8$ & & $435(78)$ & 4.7 & $4.3-5.1$ & \\
\hline Elementary school & $198(28)$ & 5.2 & $4.7-5.7$ & $n s^{a}$ & $157(28)$ & 4.5 & $3.9-5.1$ & $\mathrm{~ns}^{\mathrm{a}}$ \\
\hline Medium education & $253(35)$ & 5.1 & $4.7-5.6$ & & $225(40)$ & 4.6 & $4.0-5.1$ & \\
\hline University & $263(37)$ & 5.7 & $5.2-6.1$ & & $174(3 \mid)$ & 5.0 & $4.5-5.6$ & \\
\hline Employed & $356(50)$ & 5.4 & $5.0-5.8$ & $n s^{a}$ & $281(50)$ & 4.5 & $4.1-4.9$ & $\mathrm{~ns}^{\mathrm{a}}$ \\
\hline Retired age & $158(22)$ & 5.5 & $5.0-6.1$ & & 177 (32) & 4.9 & $4.3-5.4$ & \\
\hline Other & $203(28)$ & 5.1 & $4.5-5.7$ & & $101(18)$ & 4.9 & $4.0-5.7$ & \\
\hline Born in Sweden & $624(87)$ & 5.3 & $5.0-5.6$ & $n s^{b}$ & $497(89)$ & 4.5 & $4.2-4.8$ & $0.006^{\mathrm{b}}$ \\
\hline Born in another & $94(13)$ & 5.7 & $4.8-6.5$ & & $62(\mathrm{II})$ & 6.0 & $4.7-7.3$ & \\
\hline \multicolumn{9}{|l|}{ Physical activity } \\
\hline$\leq 0.5 \mathrm{~h} /$ week & $22 I(3 I)$ & 4.6 & $4.1-5.1$ & $<0.001^{a, c}$ & $197(35)$ & 4.0 & $3.5-4.5$ & $0.00 I^{a, d}$ \\
\hline $0.6-1.0 \mathrm{~h} /$ week & I6I (23) & 5.2 & $4.7-5.8$ & & $87(15)$ & 4.8 & $4.0-5.6$ & \\
\hline I.I-2.5 h/week & $216(30)$ & 5.9 & 5.46 .4 & & $182(32)$ & 4.9 & $4.4-5.5$ & \\
\hline$>2.5 \mathrm{~h} /$ week & $114(16)$ & 6.0 & $5.3-6.7$ & & $96(17)$ & 5.5 & $4.6-6.3$ & \\
\hline
\end{tabular}

Note: Groups with significantly $(P \leq 0.01)$ higher consumption with bolded figures.

${ }^{a}$ One-way ANOVA within the grouping variable.

b Two independent samples T-test within the grouping variable.

'Tukey HSD post test: $\leq 0.5 \mathrm{~h}$ vs. I. I $-2.5 \mathrm{~h}, P<0.00 \mathrm{I}$; $\leq 0.5 \mathrm{~h}$ vs. $>2.5 \mathrm{~h}, P<0.00 \mathrm{I}$

${ }^{\mathrm{d}}$ Tukey HSD post test: $\leq 0.5 \mathrm{~h}$ vs. $>2.5 \mathrm{~h}, P=0.00 \mathrm{I}$.

$(P<0.001)$. Also among men, those reporting $\leq 0.5 \mathrm{~h}$ $\mathrm{PA} /$ week had lower $\mathrm{F} \& \mathrm{~V}$ consumption than those reporting $\geq 2.5 \mathrm{~h} \mathrm{PA} /$ week. For more details, see Table 1 .

Consumption of different types of $\mathrm{F} \& \mathrm{~V}$, based on the self-administered 24-h recall, by gender and age group is presented in Table 2. Fresh fruits, as well as raw vegetables and salad, were consumed in the greatest amounts, and more by women than by men $(P<0.001)$. Comparisons between women and men within each age group showed that 55- to 74-year-old women consumed more fruits in total $(P \leq 0.001)$, and more fresh fruits $(P \leq 0.002)$, than men. Women between 55 and 64 years also had higher total vegetable consumption than men in the same age group $(P=0.002)$. Overall consumption of berries and cooked vegetables was relatively low, and no gender differences were shown.

The FFQ also showed that fresh F\&V were consumed most often (Table 3). More women than men in all age groups consumed fresh fruit every day $(63.5 \%$ vs. $38.9 \%$ for all age groups combined, respectively; $P<0.001$ ). Almost one half of women (48.3\%) consumed salad or raw vegetables every day compared to $28.8 \%$ among men $(P<0.001)$. Men reported a higher consumption frequency only for canned fruit $(P=0.002)$, although the overall consumption frequency was very low.

Comparisons between women and men using the web-based or pen-and-paper questionnaire showed no differences in total F\&V consumption. Age differences between these two groups could not be seen, whereas women choosing the web-based questionnaire had higher level of education.

\section{Discussion}

On average, respondents in the present study reported slightly higher $\mathrm{F} \& \mathrm{~V}$ consumption than expected based on earlier findings in Sweden $(13,14)$. Some other recent studies (25) have also reported changes in dietary habits during the past decade. However, the methodology used 
Table 2. Mean consumption of different fruit and vegetable types ( $N$ of self-reported portions/day, [99\% confidence interval]) by gender and age group (24-h recall)

\begin{tabular}{|c|c|c|c|c|c|c|c|c|}
\hline Age & Gender & $\begin{array}{c}\text { Total fruit } \\
\text { (fresh, canned, dried, frozen) }\end{array}$ & $\begin{array}{l}\text { Fresh } \\
\text { fruit }\end{array}$ & Berry & Juice & $\begin{array}{c}\text { Total vegetables } \\
\text { (salad/raw, cooked, canned) }\end{array}$ & $\begin{array}{l}\text { Salad/raw } \\
\text { vegetables }\end{array}$ & $\begin{array}{c}\text { Cooked } \\
\text { vegetables }\end{array}$ \\
\hline \multirow[t]{2}{*}{$18-24 y$} & Women & $1.7[1.3-2.2]$ & $1.5[1.1-1.9]$ & $0.2[0.0-0.3]$ & $1.0[0.6-1.3]$ & $2.3[1.7-2.8]$ & $1.5[1.0-2.0]$ & $0.3[0.1-0.5]$ \\
\hline & Men & $1.2[0.8-1.6]$ & I.I [0.7-I.5] & $0.1[0.0-0.2]$ & $1.0[0.6-1.4]$ & $1.8[1.3-2.3]$ & $1.0[0.6-1.4]$ & $0.3[-1-0.6]$ \\
\hline \multirow[t]{2}{*}{$25-34 y$} & Women & $1.8[1.4-2.1]$ & $1.6[1.3-1.9]$ & $0.2[0.0-0.4]$ & $0.7[0.4-1.0]$ & $2.3[1.8-2.9]$ & $1.5[1.1-1.8]$ & $0.4[0.2-0.6]$ \\
\hline & Men & $1.2[0.8-1.5]$ & I.I [0.8-I.4] & $0.2[0.1-0.4]$ & $0.9[0.6-1.2]$ & $2.2[1.8-2.6]$ & $1.5[1.1-1.8]$ & $0.4[0.2-0.6]$ \\
\hline \multirow[t]{2}{*}{$35-44 y$} & Women & $1.9[1.5-2.2]$ & $1.8[1.4-2.1]$ & $0.2[0.1-0.4]$ & $0.7\left[\begin{array}{ll}0.4 & 0.9\end{array}\right]$ & $2.0[1.7-2.4]$ & $1.4[1.1-1.7]$ & $0.3[0.2-0.5]$ \\
\hline & Men & $1.7[1.3-2.0]$ & $1.5[1.2-1.8]$ & $0.2[0.1-0.3]$ & $1.0[0.7-1.3]$ & $1.8[1.4-2.2]$ & I.I [0.7-1.5] & $0.3[0.2-0.5]$ \\
\hline \multirow[t]{2}{*}{$45-54 y$} & Women & $2.0[1.6-2.4]$ & $1.8[1.4-2.1]$ & $0.4[0.2-0.6]$ & $0.7[0.5-0.9]$ & $2.3[1.9-2.8]$ & $1.5[1.2-1.8]$ & $0.5[0.3-0.7]$ \\
\hline & Men & $1.7[1.3-2.0]$ & $1.5[1.2-1.8]$ & $0.2[0.1-0.4]$ & $0.6\left[\begin{array}{ll}0.4 & 0.8\end{array}\right]$ & $2.2[1.7-2.6]$ & $1.2[0.9-1.5]$ & $0.6[0.3-0.8]$ \\
\hline \multirow[t]{3}{*}{$55-64 y$} & Women & $2.4[2.0-2.8]$ & $2.2[1.8-2.6]$ & $0.3[0.1-0.5]$ & $0.7[0.5-0.9]$ & $2.4[2.0-2.7]$ & $1.4[1.2-1.7]$ & $0.7\left[\begin{array}{ll}0.4 & 0.89\end{array}\right]$ \\
\hline & Men & $1.7[1.4-2.0]$ & 1.5 [1.3-1.8] & $0.2[0.1-0.4]$ & $0.7[0.5-0.9]$ & $1.7[1.4-2.0]$ & $1.1[0.9-1.4]$ & $0.4[0.2-0.6]$ \\
\hline & & $P=0.001$ & $P=0.002$ & & & $P=0.002$ & & \\
\hline \multirow{3}{*}{$65-74$ y } & Women & $2.3[2.0-2.7]$ & $2.1[1.8-2.4]$ & $0.4[0.2-0.6]$ & $0.6\left[\begin{array}{ll}0.4 & 0.8\end{array}\right]$ & $2.2[1.8-2.5]$ & $1.2[1.0-1.5]$ & $0.7\left[\begin{array}{ll}0.4 & 0.9\end{array}\right]$ \\
\hline & Men & $1.7[1.4-1.9]$ & 1.5 [1.2-1.7] & $0.5[0.3-0.7]$ & $0.7[0.6-0.9]$ & $2.0[1.7-2.4]$ & $1.0[0.8-1.2]$ & $0.6\left[\begin{array}{ll}0.4 & 0.8\end{array}\right]$ \\
\hline & & $P<0.001$ & $P<0.001$ & & & & & \\
\hline \multirow[t]{2}{*}{$75-84$ y } & Women & $2.4[1.9-2.8]$ & $2.2[1.8-2.6]$ & $0.6[0.2-1.0]$ & $0.6[0.3-0.9]$ & $1.9[1.5-2.4]$ & $1.1[0.8-1.4]$ & $0.5[0.3-0.8]$ \\
\hline & Men & $1.9[1.5-2.2]$ & $1.7[1.4-2.1]$ & $0.4[0.3-0.6]$ & $0.6\left[\begin{array}{ll}0.4 & 0.8\end{array}\right]$ & $1.8[1.5-2.2]$ & $1.0[0.7-1.3]$ & $0.6\left[\begin{array}{ll}0.4 & 0.8\end{array}\right]$ \\
\hline \multirow[t]{3}{*}{ All ages } & Women & $2.1[1.9-2.2]$ & $1.9[1.7-2.0]$ & $0.3[0.2-0.4]$ & $0.7[0.6-0.8]$ & $2.2[2.0-2.4]$ & $1.4[1.3-1.5]$ & $0.5\left[\begin{array}{ll}0.4 & 0.6\end{array}\right]$ \\
\hline & Men & $1.6[1.4-1.9]$ & $1.5[1.3-1.6]$ & $0.3[0.2-0.4]$ & $0.8[0.7-0.9]$ & $1.9[1.8-2.1]$ & $1.1[1.0-1.3]$ & $0.5\left[\begin{array}{ll}0.4 & 0.6\end{array}\right]$ \\
\hline & & $P<0.001$ & $P<0.001$ & & & $P=0.003$ & $P<0.001$ & \\
\hline
\end{tabular}

Note: $P$-values for gender differences within age group. Bolded figures are statistically significant differences. 
Table 3. Percentages of daily users ${ }^{\mathrm{a}}$ of different fruit and vegetable types and gender differences in $\mathrm{F} \& \mathrm{~V}$ consumption frequencies within age groups (food frequency questionnaire)

\begin{tabular}{|c|c|c|c|c|c|c|c|c|c|c|}
\hline Age & Gender & Fresh fruit & Dried fruit & Canned fruit & Juice & Berries & $\begin{array}{c}\text { Salad/raw } \\
\text { vegetables }\end{array}$ & $\begin{array}{c}\text { Cooked } \\
\text { vegetables }\end{array}$ & $\begin{array}{c}\text { Canned } \\
\text { vegetables }\end{array}$ & Beans \\
\hline \multirow[t]{3}{*}{$18-24 y$} & Women & 48.9 & 6.6 & 3.3 & 20.0 & 5.5 & 41.3 & 7.7 & 6.6 & 6.5 \\
\hline & Men & 19.6 & 5.9 & 2.0 & 22.0 & 2.0 & 29.4 & 6.0 & 0 & 2.0 \\
\hline & & $P=0.003^{b}$ & & & & & & & & \\
\hline \multirow[t]{3}{*}{$25-34 y$} & Women & 56.5 & 7.3 & 1.9 & 19.8 & 1.8 & 45.0 & 13.0 & 3.7 & 1.9 \\
\hline & Men & 35.5 & 6.6 & 0 & 15.8 & 0 & 28.4 & 2.7 & 1.4 & 1.4 \\
\hline & & $P<0.00 I^{b}$ & & & & & & & & \\
\hline \multirow[t]{3}{*}{$35-44 y$} & Women & 60.6 & 7.3 & 0 & 18.3 & 2.7 & 54.1 & 12.7 & 4.7 & 1.8 \\
\hline & Men & 38.6 & 8.6 & 0 & 25.7 & 1.4 & 34.8 & 5.8 & 2.9 & 1.4 \\
\hline & & $P<0.00 I^{b}$ & & & & & $P<0.001^{b}$ & & & \\
\hline \multirow{3}{*}{$45-54$ y } & Women & 65.5 & 9.9 & 0 & 20.5 & 9.9 & 54.5 & 11.8 & 1.8 & 3.7 \\
\hline & Men & 37.0 & 0 & 0 & 24.1 & 0 & 29.6 & 3.8 & 2.5 & 4.9 \\
\hline & & $P<0.00 I^{b}$ & $P=0.00 I^{b}$ & & & $P=0.007^{\mathrm{b}}$ & $P<0.00 I^{b}$ & & & \\
\hline \multirow[t]{3}{*}{ 55-64 y } & Women & 65.1 & 14.3 & 0 & 23.4 & 5.5 & 48.0 & 12.7 & 0.8 & 1.6 \\
\hline & Men & 43.5 & 12.0 & 0 & 23.3 & 8.0 & 33.3 & 7.1 & 2.3 & 3.5 \\
\hline & & $P<0.00 I^{b}$ & & $P=0.002^{\mathrm{b}}$ & & & $P<0.001^{b}$ & & & \\
\hline \multirow[t]{3}{*}{ 65-74 y } & Women & 77.7 & 17.6 & 0 & 31.3 & 14.3 & 50.9 & 12.1 & 1.0 & 3.0 \\
\hline & Men & 46.1 & 12.6 & 0 & 22.7 & 7.1 & 35.3 & 5.0 & 2.0 & 1.0 \\
\hline & & $P<0.00 I^{b}$ & & & & & & $P=0.00 I^{b}$ & & \\
\hline \multirow[t]{3}{*}{ 75-84 y } & Women & 71.0 & 19.6 & 0 & 26.9 & 11.3 & 38.6 & 10.7 & 1.6 & 1.9 \\
\hline & Men & 41.6 & 10.7 & 1.3 & 24.1 & 14.1 & 30.6 & 13.8 & 1.2 & 2.5 \\
\hline & & $P<0.00 I^{b}$ & & & & & & & & \\
\hline \multirow[t]{3}{*}{ All ages } & Women & 63.5 & 11.0 & 0.3 & 22.6 & 6.9 & 48.3 & 11.7 & 1.7 & 2.9 \\
\hline & Men & 38.9 & 8.3 & 0.4 & 22.6 & 5.1 & 28.8 & 6.4 & 1.8 & 2.4 \\
\hline & & $P<0.00 I^{b}$ & & & & & $P<0.001^{b}$ & $P=0.001^{\mathrm{b}}$ & & \\
\hline
\end{tabular}

Note: Bolded figures are statistically significant differences.

${ }^{a}$ Once/day + two times/day + more than twice a day.

bMann-Whitney test for gender differences in consumption frequencies (eight categories as presented in Methods). 
in the present study differed from the latest national food intake survey (13), and the results are not directly comparable with each others. In line with our findings, previous studies have also shown that men tend to have lower F\&V consumption than women (15-18). A study from Finland showed that gender differences in vegetable consumption have actually increased (34). Both the selfadministered 24-h recall and FFQ showed higher F\&V consumption in women when all age groups were combined, while the data from the FFQ showed larger differences between women and men within different age groups. Earlier studies have shown that men slightly underestimate their $\mathrm{F} \& \mathrm{~V}$ consumption, whereas the opposite applies to women (33). Thus, the gender differences revealed here may turn out to be slightly less significant, but the similar findings from two measures indicate that these differences actually exist.

The self-administered 24-h recall showed higher consumption of fresh fruit particularly for middle-aged and older women, which is in line with results from a recent Finnish study (18). On the other hand, the FFQ showed that women in many age groups were more frequent consumers of not only fruit, but also salad and other raw vegetables. F\&V seem to be most popular when they are fresh. It seems that Swedes are not used to including F\&V in mixed dishes, but rather eat them separately as they are. On the other hand, the authors are aware of the limitations of the study questionnaire, where only one open-ended item on mixed dishes was included. This may have led to some underreporting, indicating that actual consumption may be higher than reported.

The present study further showed some interesting differences between women and men in factors associated with F\&V consumption. Men born outside Sweden had higher F\&V consumption than men born in Sweden did, which may reflect the different habits associated with other food cultures. For instance, non-Western immigrants in Denmark have been reported to have higher odds for daily consumption of cooked and raw vegetables (35), and Iranians living in Sweden also show higher consumption of F\&V (36). However, because the specific country of birth is not reported in the present study, no conclusions regarding specific food cultures can be drawn.

PA was the only variable of those investigated that was associated with total $\mathrm{F} \& \mathrm{~V}$ consumption in both genders. Therefore, we may speculate that $\mathrm{F} \& \mathrm{~V}$ consumption is an integrated part of a lifestyle in which PA also plays an important role. However, the limitations of only using a single question to measure level of PA are recognized (25), and more detailed assessments are encouraged to gain better understanding on the associations between $\mathrm{PA}$ and consumption of $\mathrm{F} \& \mathrm{~V}$.

From a methodological point of view, the FFQ may enable better prediction of average consumption over a longer time period, whereas the self-administered 24-h recall was used to more accurately assess consumption over a specified period. Also, there is a certain risk of over-reporting actual consumption in the FFQ, but this was not regarded as a problem when ranking individuals and subgroups according to their consumption (37). In addition, although consumption has not been reported in grams, consumption frequency as such is a good measure of consumption, because portion sizes have not been reported to differ between high and low consumers (12).

We are aware of the possibility of a type I error for false significant findings (38) due to the many significance tests conducted. However, because the main findings are significant at a level well below $1 \%$, and both dietary assessment measures showed similar findings, this is not regarded as a problem. In the present study, all days of the week were equally represented in the data (data not shown), which eliminates the possible bias caused by consumption differences across the weekdays. Seasonal consumption variation can also be excluded as a confounding factor, because the data consist of roughly equally large groups of participants in different seasonal groups. The aim was to show an average consumption of the population over one year and not to compare seasonal variation as such.

A nationwide random sample is not a widely used data collection method. The present results have to be interpreted with caution owing to the relatively large proportion of non-respondents (49\%), although the drop-out rate was nearly as high in the latest nationwide dietary survey used as a reference here (13). Men in general, and the youngest age group (18-24 years), but also the oldest women (75-84 years) were somewhat underrepresented in the present survey. However, the relatively high total number of respondents should be representative of actual $\mathrm{F} \& \mathrm{~V}$ consumption levels in Sweden, although in most cases, respondent selection in postal surveys probably leads to overrepresentation of people who are more interested in the topic, or who already have healthier dietary habits. This may have resulted in underestimating real differences between different sociodemographic groups.

The cross-sectional design limits conclusions about the temporal or causal nature of the findings, but the study design can provide answers that address the study aims. From a data collection perspective, the present study gives valuable experience in using a web-based questionnaire as an alternative response measure. Giving respondents the opportunity to choose between a traditional pen-and-paper and a web-based questionnaire was intended to increase the response rate and attract particularly younger respondents, but age differences could not be identified in the present study (data not shown). In accordance with Danish experiences (39), the majority of respondents preferred the paper version to the web-based 
questionnaire. However, using the Internet may still be worthwhile, as it saves both environmental and labor resources.

\section{Conclusions}

The present study showed average F\&V consumption close to the recommended level of five portions per day. Fresh F\&V showed the highest consumption, whereas berries and processed F\&V products were less popular. University education was positively associated with higher F\&V consumption for women, and men born outside Sweden showed higher consumption than did men born in Sweden. Respondents who reported more hours per week engaged in doing PA had higher F\&V consumption in both genders. Although total consumption seems to have increased, the role of other underlying factors besides the sociodemographic factors and PA studied here remains unclear. In addition, other perspectives on F\&V consumption, such as possible seasonal variation in availability of different $F \& V$ types, should be taken into consideration when implementing new dietary interventions or guidelines.

\section{Acknowledgements}

This study was supported by grants from Stiftelsen Uppsala Hushållskolas fond and Fackskolans elevförbund. The authors would like to thank all who took part in this study. All the authors were responsible for fund raising and study design. A.S. performed the data collection, data analysis, and drafted the paper as part of her $\mathrm{PhD}$ thesis at Uppsala University. M.N. and A.A. critically revised the manuscript. All the authors approved the final version.

\section{Conflict of interest and funding}

The authors have not received any funding or benefits from industry to conduct this study.

\section{References}

1. Djoussé L, Arnett DK, Coon H, Province MA, Moore LL, Ellison RC. Fruit and vegetable consumption and LDL cholesterol: the National Heart, Lung, and Blood Institute Family Heart Study. Am J Clin Nutr 2004; 79: 213-7.

2. John JH, Ziebland S. Reported barriers to eating more fruit and vegetables before and after participation in a randomized controlled trial: a qualitative study. Health Educ Res 2004; 19: $165-74$.

3. Diet, nutrition and the prevention of chronic diseases. World Health Organization Technical Report Series 916; 2003.

4. Riboli E, Norat T. Epidemiologic evidence of the protective effect of fruit and vegetables on cancer risk. Am J Clin Nutr 2003; 78: 559S-69S

5. Nomura AMY, Wilkens LR, Murphy SP, Hankin JH, Henderson BE, Pike MC, et al. Association of vegetable, fruit, and grain intakes with colorectal cancer: the Multiethnic Cohort Study. Am J Clin Nutr 2008; 88: 730-7.

6. Wu H, Dai Q, Shrubsole MJ, Ness RM, Schlundt D, Smalley WE, et al. Fruit and vegetable intakes are associated with lower risk of colorectal adenomas. J Nutr 2009; 139: 340-4.
7. He F, Nowson CA, MacGregor GA. Fruit and vegetable consumption and stroke: meta-analysis of cohort studies. Lancet 2006; 367: 320-6.

8. Rissanen TH, Voutilainen S, Virtanen JK, Venho B, Vanharanta $\mathrm{M}$, Mursu J, et al. Low intake of fruits, berries and vegetables is associated with excess mortality in men: the Kuopio ischaemic heart disease risk factor (KIHD) study. J Nutr 2003; 133: 199204.

9. The World Health Report 2002. Reducing risks, promoting healthy life. Geneva, Switzerland: World Health Organization; 2003.

10. Nordic Nutrition Recommendations. Integrating nutrition and physical activity. Copenhagen: Nordic Council of Ministries; 2004.

11. Food, Nutrition, Physical Activity, and the Prevention of Cancer. A global perspective. Washington, DC: World Cancer Research Fund/American Institute for Cancer Research; 2007.

12. Ashfield-Watt PA, Welch AA, Day NE, Bingham SA. Is five-aday' an effective way of increasing fruit and vegetable intakes? Public Health Nutr 2004; 7: 257-61.

13. Livsmedelsverket. Dietary habits and nutrient intake in Sweden 1997-98. The second national food consumption survey; 2003.

14. Boström G, Nykvist K. Nationella folkhälsoenkäten Hälsa på lika villkor [National Public Health Questionnaire. Health on Equal Terms]. Östersund, Sweden: Swedish National Institute of Public Health; 2006.

15. Boström G, Nykvist K. Levnadsvanor och hälsa - de första resultaten från den nationella folkhälsoenkäten Hälsa på lika villkor [Ways of living and health - the first results from the national public health questionnaire Health on equal terms]. Östersund, Sweden: Swedish National Institute of Public Health; 2004.

16. Johansson L, Thelle DS, Solvoll K, Bjorneboe GE, Drevon CA. Healthy dietary habits in relation to social determinants and lifestyle factors. Br J Nutr 1999; 81: 211-20.

17. Baker AH, Wardle J. Sex differences in fruit and vegetable intake in older adults. Appetite 2003; 40: 269-75.

18. Prattala R, Paalanen L, Grinberga D, Helasoja V, Kasmel A, Petkeviciene J. Gender differences in the consumption of meat, fruit and vegetables are similar in Finland and the Baltic countries. Eur J Public Health 2007; 17: 520-5.

19. Lallukka T, Laaksonen M, Rahkonen O, Roos E, Lahelma E. Multiple socio-economic circumstances and healthy food habits. Eur J Clin Nutr 2007; 61: 701-10.

20. Wallstrom P, Wirfalt E, Janzon L, Mattisson I, Elmstahl S, Johansson U, et al. Fruit and vegetable consumption in relation to risk factors for cancer: a report from the Malmo diet and cancer study. Public Health Nutr 2000; 3: 263-71.

21. Donkin AJ, Johnson AE, Morgan K, Neale RJ, Page RM, Silburn RL. Gender and living alone as determinants of fruit and vegetable consumption among the elderly living at home in urban Nottingham. Appetite 1998; 30: 39-51.

22. Trudeau E, Kristal AR, Li S, Patterson RE. Demographic and psychosocial predictors of fruit and vegetable intakes differ: implications for dietary interventions. J Am Diet Assoc 1998; 98: $1412-7$.

23. Casagrande SS, Wang Y, Anderson C, Gary TL. Have Americans increased their fruit and vegetable intake? The trends between 1988 and 2002. Am J Prev Med 32; 2007: 257-63.

24. Deshmukh-Taskar P, Nicklas TA, Yang SJ, Berenson GS. Does food group consumption vary by differences in socioeconomic, demographic, and lifestyle factors in young adults? The Bogalusa heart study. J Am Diet Assoc 2007; 107: 223-34.

25. Estaquio C, Druesne-Pecollo N, Latino-Martel P, Dauchet L, Hercberg S, Bertrais S. Socioeconomic differences in fruit and vegetable consumption among middle-aged French adults: 
adherence to the 5 a day recommendation. $\mathbf{J}$ Am Diet Assoc 2008; 108: 2021-30.

26. Groth MV, Fagt S, Brondsted L. Social determinants of dietary habits in Denmark. Eur J Clin Nutr 2001; 55: 959-66.

27. Irala-Estevez JD, Groth M, Johansson L, Oltersdorf U, Prattala R, Martinez-Gonzalez MA. A systematic review of socioeconomic differences in food habits in Europe: consumption of fruit and vegetables. Eur J Clin Nutr 2000; 54: 706-14.

28. Hjartaker A, Lund E. Relationship between dietary habits, age, lifestyle, and socio-economic status among adult Norwegian women. The Norwegian women and cancer study. Eur J Clin Nutr 1998; 52: 565-72.

29. Lennartsson D, Forssén K. Food sales 2007, HA24. Stockholm, Sweden: Statistics Sweden; 2008.

30. Gustafsson B, Hermerén G, Petersson B. Good research practice - What is this? Views, guidelines and examples. Vetenskapsrådets rapportserie. Stockholm: The Swedish Research Council; 2006.

31. Kristjansdottir AG, Andersen LF, Haraldsdottir J, de Almeida MD, Thorsdottir I. Validity of a questionnaire to assess fruit and vegetable intake in adults. Eur J Clin Nutr 2006; 60: 408-15.

32. SPSS. 16.0 ed. Chicago: SPSS Inc.; 2008.

33. Ovaskainen ML, Paturi M, Reinivuo H, Hannila ML, Sinkko $\mathrm{H}$, Lehtisalo J, et al. Accuracy in the estimation of food servings against the portions in food photographs. Eur J Clin Nutr 2008; 62: 674-81.

34. Roos E, Talala K, Laaksonen M, Helakorpi S, Rahkonen O, Uutela A, et al. Trends of socioeconomic differences in daily vegetable consumption, 1979-2002. Eur J Clin Nutr 62; 2007: 823-33.
35. Hansen AR, Ekholm O, Kjoller M. Health behaviour among non-Western immigrants with Danish citizenship. Scand J Public Health 2008; 36: 205-10.

36. Koochek A. Elderly Iranians in Sweden. The impact of migration on risk factors for cardiovascular disease [Doctoral dissertation]. Stockholm: Karolinska Institutet; 2008.

37. Bogers RP, Dagnelie PC, Westerterp KR, Kester ADM, van Klaveren JD, Bast A, et al. Using a correction factor to correct for overreporting in a food-frequency questionnaire does not improve biomarker-assessed validity of estimates for fruit and vegetable consumption. J Nutr 2003; 133: 1213-9.

38. Kirkwood BR, Sterne JAC. Essential medical statistics, 2nd ed. Malden, MA: Blackwell Science; 2003.

39. Kongsved SM, Basnov M, Holm-Christensen K, Hjollund NH. Response rate and completeness of questionnaires: a randomized study of Internet versus paper-and-pencil versions. J Med Internet Res 2007; 9: e25.

\footnotetext{
*Anna-Mari Simunaniemi

Department of Food, Nutrition and Dietetics

University of Uppsala

$\mathrm{PO}$ Box 560

SE-75I 22 Uppsala

Sweden

Tel: $+46|847| 2315$

Fax: $+461847 \mid 2261$

Email: anna-mari.simunaniemi@ikv.uu.se
} 